\title{
Perancangan dan Implementasi Mesin Pengolah Kumbu Bakpia Berbasis Teknologi Automasi
}

\author{
Design and Implementation Processing Machine for Kumbu Bakpia \\ Based on Automation Technology
}

\author{
Ari Sugiharto ${ }^{1}$ \\ Program Studi Teknik Komputer \\ Universitas Teknologi Yogyakarta \\ Kampus 1 UTY Jl. Siliwangi, \\ Sendangadi, Mlati, Sleman, \\ Yogyakarta \\ ari.sugiharto@uty.ac.id
}

\author{
Yohanes Anton Nugroho ${ }^{2}$ \\ Program Studi Teknik Industri \\ Universitas Teknologi Yogyakarta \\ Kampus 2 UTY Jl. Glagahsari No. \\ 63 Yogyakarta \\ yohanesanton@uty.ac.id
}

\author{
Ari Zaqi Al Faritsy ${ }^{3}$ \\ Program Studi Teknik Industri \\ Universitas Teknologi Yogyakarta \\ Kampus 2 UTY Jl. Glagahsari No. \\ 63 Yogyakarta \\ ari_zaqi@uty.ac.id
}

\begin{abstract}
Abstrak--Makalah ini akan menyampaikan bagaimana perancangan dan implementasi mesin pengolah kacang hijau menjadi kumbu bakpia. Mesin ini telah diimplementasikan pada kelompok industri bakpia skala kecil di Dusun Jurug Kabupaten Bantul. Proses produksi secara manual yang dilakukan dalam waktu 8 jam mampu menghasilkan 2 kg kumbu bakpia atau 200 butir bapia. Makalah ini mencoba menunjukkan hasil perancangan dan implementasi mesin pengolah kumbu bakpia yang dikembangkan menggunakan teknologi automasi berbasis mikrokontroler. Melalui mesin pengolah kumbu bakpia yang dibuat proses pengolahan kacang hijau menjadi kumbu bakpia matang dapat dikerjakan lebih efektif dan efisien. Modul automasi yang dikembangkan mampu disesuaikan dengan jumlah bahan yang akan diproses. Apabila mesin digunakan dalam kapasitas maksimal, maka dalam waktu 8 jam penggunaan dapat memproses $24 \mathrm{~kg}$ kumbu bakpia.
\end{abstract}

Kata Kunci-- Automasi, Mikrokontroler, Kacang Hijau, Bakpia

Abstract--This paper will present how to design and implement a mung beans processing machine to produce bakpia filling. This machine has been implemented in the small-scale bakpia industry group in Jurug, Bantul Regency. The manual production process carried out within 8 hours can produce $2 \mathrm{~kg}$ of bakpia or 200 bakpia. This paper tries to show the results of the design and implementation of filling bakpia processing machines which developed using microcontroller-based automation technology. Through bakpia processing machines, the process of processing mung beans into cooked bakpia filling can be done more effective and efficiently. The automation module developed can be adjusted to the amount of material to be processed, if the machine is used in maximum capacity, then within 8 hours of use can process $24 \mathrm{~kg}$ of mung beans.

Keywords:Automation, Microcontroller, Bakpia Filling, Mung Beans

\section{PENDAHULUAN}

Produksi bakpia di dusun Jurug, Desa Bangunharjo, Kecamatan Sewon, Kabupaten Bantul, Daerah Istimewa Yogyakarta dikerjakan oleh ibu-ibu rumah tangga secara manual. Berdasarkan usahanya industri ini dapat dikategorikan sebagai industri kecil dan mikro. Pada kondisi awal terdapat 6 industri bakpia yang masing-masing hanya mampu mengolah bakpia dengan kapasitas maksimal $2 \mathrm{~kg}$ kumbu bakpia/industri/hari atau sekitar 200 butir bakpia untuk masing-masing industri per harinya. Rendahnya kapasitas produksi disebabkan pengolahan kumbu bakpia masih dilakukan secara manual dan membutuhkan waktu sekitar 1,5 jam untuk proses pemasakan dan pengadukan kumbu. Proses pengadukan ini sangat melelahkan pengrajin, karena harus mengaduk secara terus menurus selama proses berjalan.

Berdasarkan permasalahan tersebut telah dilakukan perancangan alat atau mesin kumbu bakpia dengan menggunakan alat oleh Prayitno [1] dengan menggunakan pendekatan VDI 2221 dan Kano. Hasil dari penelitian ini adalah berupa protoype mesin pengolah kumbu bakpia berbahan kacang ijo dengan volume bak pengaduk sebesar 31,84 liter, sehingga mampu digunakan untuk mengaduk dalam kapasitas maksimal $3 \mathrm{~kg}$ dalam waktu 60 menit. Mesin yang dikembangkan tersebut telah dapat meningkatkan produksi dan tenaga yang digunakan. Meskipun demikian dalam penggunaanya masih belum optimal karena operator produksi harus memantau proses yang berjalan secara terus menerus, sehingga tidak dapat mengerjakan pekerjaan lainnya.

Perancangan ulang mesin pengolah kumbu bakpia dilakukan dengan menggunakan pendekatan sistematis (systematic system approach) yang diinspirasi Pahl dan Beitz. Pahl dan Beitz mendiskripsikan kegiatan perancangan secara sistematis ke dalam 4 kegiatan atau fase, yaitu perencanaan dan penjelasan tugas, perancangan konsep produk, perancangan bentuk produk (embodiment design), dan Perancangan detail. Pendekatan sistematis menurut Pahl dan Beitz [2] didasarkan pada empat bidang desain utama, yaitu klarifikasi tugas, desain konseptual, perwujudan desain, dan detail desain. Pendekatan sistematis yang dikembangkan dalam metode Pahl dan Beitz dapat dilihat sebagai pendekatan dari perilaku desain mekanik [3]. Model proses desain teknik 
yang sistematis bertujuan untuk memudahkan menemukan desain yang optimal bagi produk yang akan dibuat. Agar didapatkan cakupan solusi yang paling luas, perlu dilakukan pencarian solusi dengan cara yang terstruktur dan sistematis [4].

Beberapa pengembangan produk yang menggunakan pendekatan sistematis ini adalah [5] dan [6]. Dimana pada pengembangan Automated Test Systems (ATS) terbukti mampu meningkatkan keandalan dan produktivitas kegiatan pengujian dalam berbagai tahap siklus pengembangan produk dan manufaktur, di mana tes yang berbeda diperlukan untuk mengantisipasi dan memvalidasi produk dan kinerja subsistemnya, serta jaminan yang menghasilkan unit dikirim bebas dari cacat kepada pelanggan [5]. Beberapa penelitian lain yang mencoba mengembangkan produk menggunakan pendekatan sistematis dalam merancang berbagai produk diantaranya adalah [7], [8] dan [9]. Sementara [10] menggunakan metode hybrid yang mengkolaborasikan antara metode TRIZ dan pendekatan sistematis.

Berdasarkan kondisi tersebut, maka dilakukan perancangan ulang alat pengolah kumbu bakpia menggunakan pendekatan sistematis Pahl dan Beitz, dimana dalam perancangannya digunakan modul automasi berbasis mikrokontroler yang dikembangkan dengan platform Arduino IDE untuk membantu pengguna agar dapat mengerjakan pekerjaan dengan lebih efektif dan efisien. Dalam alat yang dirancang, pengguna dapat memilih pengaturan sesuai dengan jumlah kacang ijo yang akan diproses dengan pilihan $1 \mathrm{Kg}, 2$ $\mathrm{Kg}$, atau $3 \mathrm{Kg}$. Melalui penentuan pilihan ini waktu penggunaan akan dapat menyesuaikan secara otomatis dan pengguna akan dapat memahami

\section{BAHAN DAN METODA}

Tahap pengembangan dan perancangan alat pengolah kumbu bakpia dilakukan dengan menggunakan tahapan pendekatan sistematis Pahl dan Beitz [2]. Adapun hasil yang didapatkan pada masing-masing tahapan adalah sebagai berikut:

\section{Klarifikasi Tugas}

Pada perencanaan ini dikumpulkan semua informasi tentang persyaratan (requirements) yang harus dipenuhi oleh produk sehingga dapat memunculkan sebuah ide atau gagasan perancangan. Adapun hal yang diharapkan dari mesin pengolah kumbu bakpia yang akan dikembangkan adalah dapat memiliki kapasitas pengolahan proses hingga $3 \mathrm{Kg}$, bahan yang digunakan aman untuk pangan dan tidak berkarat, daya yang dibutuhkan dibawah 900 Watt, mudah dioperasikan, mudah dibersihkan.

\section{Desain Konseptual}

Perancangan desain konseptual ini meliputi gambaran perancangan, pembuatan struktur fungsi, pencarian dan kombinasi prinsip solusi, pemilihan kombinasi yang sesuai, pembuatan varian konsep, serta evaluasi. Dengan memperhitungkan yang paling mungkin diwujudkan sesuai dengan spesifikasi rancangan yang diinginkan maka dipilih didapatkan rancangan alat pengolah kumbu bakpia.

\section{Perwujudan Desain}

Perwujudan alat pengolah kumbu bakpia disusun sesuai dengan persyaratan lain yang harus dipenuhi oleh alat. Langkah perwujudan desain merupakan proposisi umum untuk dekomposisi fungsional yang mempertimbangkan aspek yang relevanyang biasanya ditemukan dalam alat pengolah kumbu bakpia. Perwujudan desain alat dilakukan dalam 3 bagian, yaitu alat kumbu bakpia, perangkat keras dan perangkat lunak. Perwujudan desain dari sistem fisik alat pengolah kumbu bakpia desain rangka, transmisi, penggunaan energy listrik, penentuan putaran, penentuan posisi sensor/aktuator. Perwujudan desain perangkat keras (hardware) meliputi: transmisi sinyal input sensor dan sinyal output aktuasi, masukan pengguna, dan penyediaan kapasitas komputasi untuk mengeksekusi perintah-perintah perangkat lunak. Sementara perwujudan desain untuk perangkat lunak meliputi inisialisasi sistem uji, pemeriksaan pengoperasian yang aman; mengelola antarmuka pengguna, menjalankan (s) algoritma pengujian (s), mengelola I / O sinyal (driver).

\section{Detail Desain}

Dengan memperhitungkan yang paling mungkin diwujudkan sesuai dengan spesifikasi rancangan yang diinginkan maka dipilih beberapa komponen dari mesin.

\section{HASIL DAN PEMBAHASAN}

Berdasarkan detail desain fase peracangan metode Pahl and Beitz didapatkan hasil berupa u pulley belt 1 tingkat, gear box 1:30, dinamo 1400Rpm, 1/4Hp, 220V, $50 \mathrm{~Hz}$, rangka profil L, kompor 1 tungku, v-belt seri A, bak pengaduk setengah lingkaran, poros pengaduk poros kipas, rantai gear box 428, gear mata 14. Adapun hasil perancangannya ditunjukkan pada Gambar 1.

Setelah didapatkan hasil perancangan alat selanjutnya dilakukan perakitan modul automasi untuk mendukung kinerja alat yang dilakukan. Adapun peralatan/komponen yang digunakan dalam penelitian ini adalah: Arduino Uno R3, Sensor Suhu LM35, Driver Control Servo, Kabel jumper, Buzzer, LCD 20 x 4, I2C Module, Button, Casing, Papan Triplek, Catu daya Adapun skema dari komponen yang digunakan dalam modul automatis mesin pengolah kumbu bakpia ditunjukkan dalam Gambar 2 


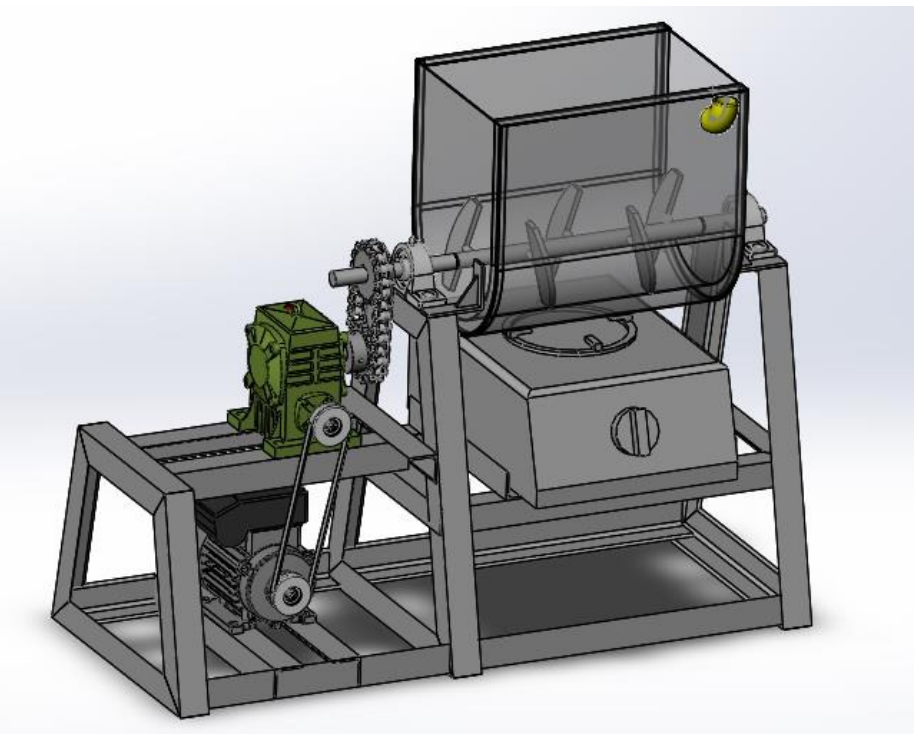

Gambar 1. Hasil Rancangan Alat

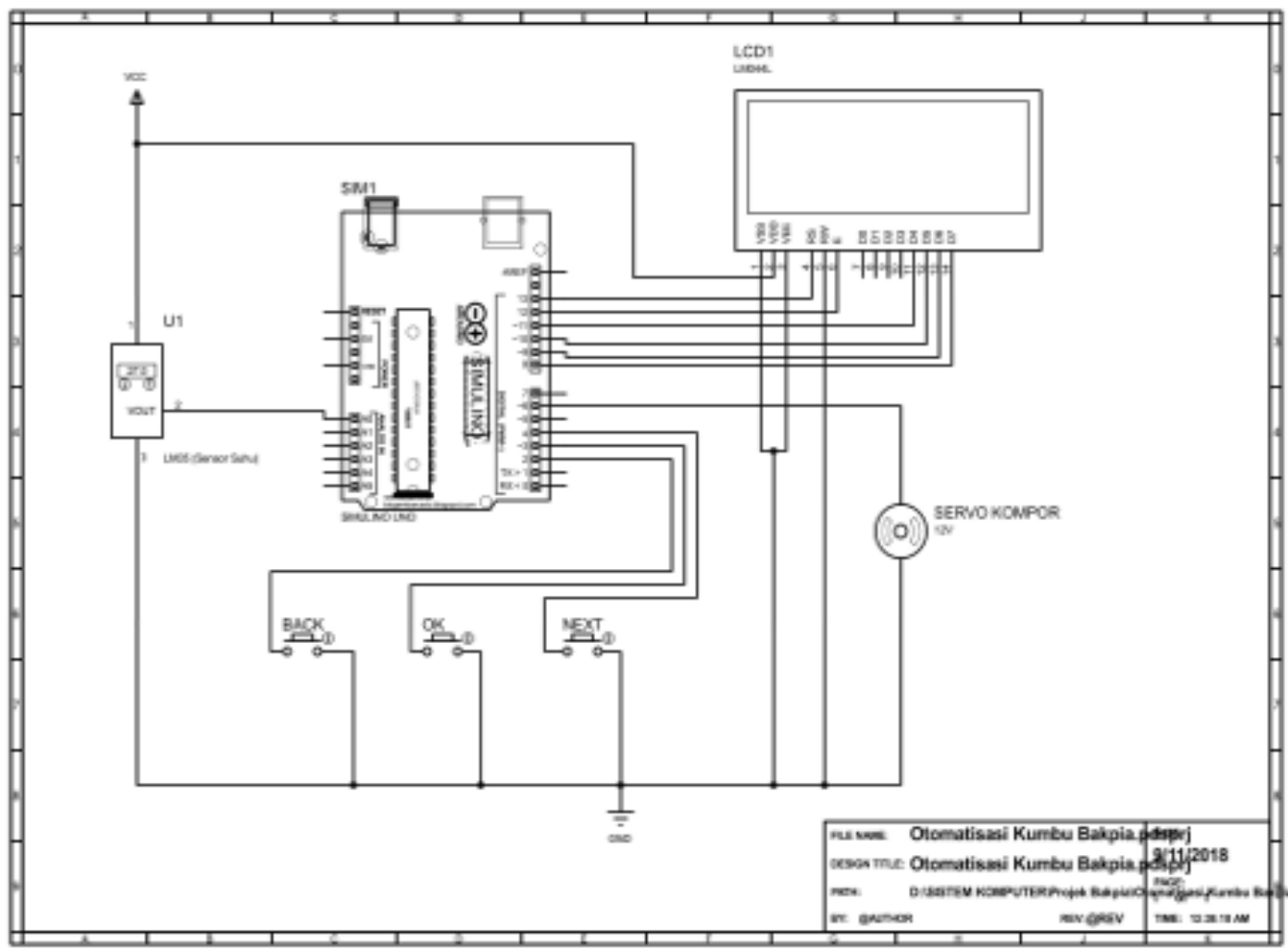

Gambar 2. Modul automatis alat pengolah kumbu bakpia

Langkah yang dilakukan untuk melakukan pengembangan modul automatis mesin pengolah kumbu bakpia adalah:

1. Melakukan pemrogram 3 button agar terhubung ke Arduino Uno, button 1 ke pin 6 , button2 ke pin 5, dan button3 ke pin 4. Pemrograman ini dilakukan dengan tujuan agar apabila salah satu button ditekan oleh pengguna maka akan ada satu perintah telah dijalankan.
2. Menghubungkan buzzer ke pin 8 Arduino Uno. Hal ini bertujuan untuk memberikan penanda bunyi bagi pengguna, ketika pengguna menekan salah satu button.

3. Menghubungkan sensor suhu LM35 ke pin A0 Arduino Uno dengan bantuan kabel jumper sepanjang 1,5 meter. Sensor suhu inilah nanti yang berfungsi untuk mendeteksi suhu api kompor. 
4. Menghubungkan servo driven control ke pin 11 pada Arduino Uno. Servo control ini yang nantinya akan berfungsi sebagai pengontrol besar kecil dan nyala mati kompor.

5. Menghubungkan 16 pin LCD dengan I2C Module yang berfungsi mempermudah komunikasi antara arduino dengan LCD, selanjutnya hubungkan pin SDA dan SCL pada pin A4 dan A5 pada Arduino. Pin Vin dan pin GND kemudian dihubungkan dengan rangkaian paralel pin Vout (tegangan) dan GND (Ground) dari komponen servo, button, serta sensor.
6. Apabila semua komponen telah terpasang dan terintegrasi pada program, selanjutnya dilakukan pemasangan catu daya ke saklar, hal ini berfungsi untuk lebih mengurangi kecelakaan user dalam menghidupkan mesin pengaduk.

7. Langkah terakhir adalah memberi pelindung komponen utama (dibagian motor) supaya komponen lebih aman dan jauh dari hal hal yang dapat merusak komponen.

8. Alat mati kompor otomatis sudah siap digunakan sesuai dengan langkah kerja penggunaan.

Hasil dari pembuatan modul automasi dari mesin pengolah kumbu bakpia yang dirancang ditunjukkan pada Gambar 3.

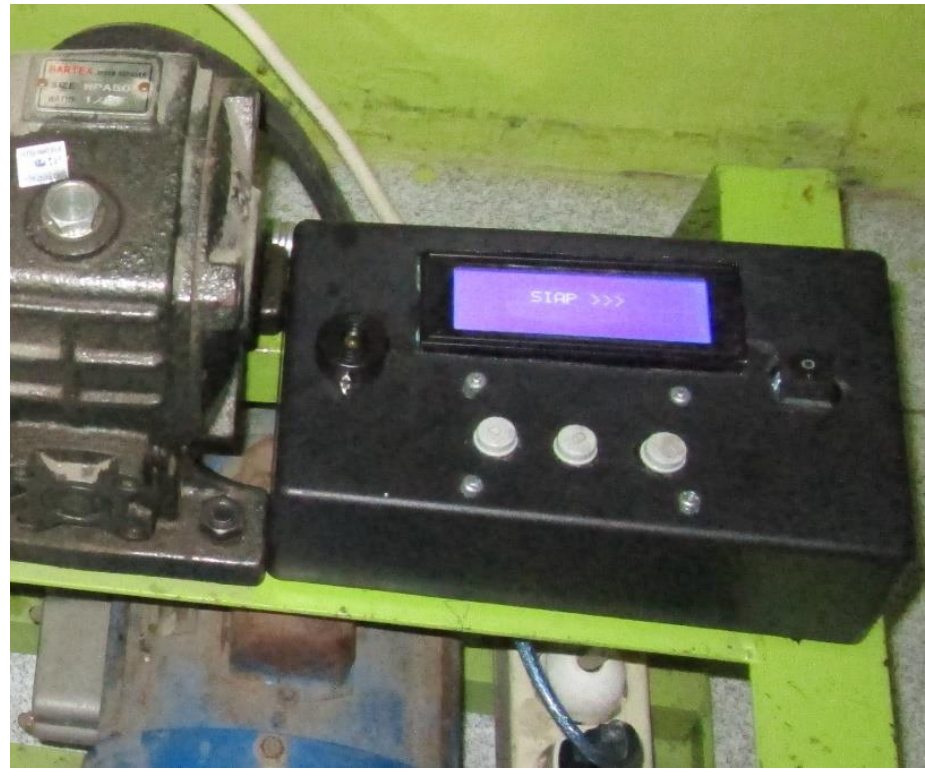

Gambar 3. Modul Automasi

Berdasarkan hasil dari perancangan modul automasi, selanjutnya dapat ditentukan urutan langkah-langkah yang dikerjakan oleh masing-masing komponen sebagai berikut:

1. Arduino membaca komponen-komponen yang terhubung seperti buzzer, button, Control Valve, dan Sensor.

2. Buzzer akan berbunyi sebanyak dua kali untuk memastikan pengguna bahwa kompor siap untuk dinyalakan dan margarine telah siap dimasukkan.

3. Kompor siap dinyalakan dengan api besar dengan output servo $90^{\circ}$.

4. LCD akan menampilkan 3 kondisi menu:

Kondisi 1 untuk pemrosesan $1 \mathrm{~kg}$

Kondisi 2 untuk pemrosesan $2 \mathrm{~kg}$

Kondisi 3 untuk pemrosesan $3 \mathrm{~kg}$

Pengguna akan menentukan pilihan sesuai dengan jumlah bahan kumbu bakpia yang digunakan.

5. Modul akan embaca data input dari 3 kondisi menu, dengan bantuan 3 button input OK untuk memilih, NEXT untuk menggeser menu selanjutnya, dan BACK untuk kembali ke menu sebelumnya

6. Pada tahap ini dilakukan pengaturan nyala api besar oleh serci

7. Sensor membaca suhu untuk indikator nyala api oleh servo.
8. Arduino akan menerima input data suhu dari sensor. Apabila data suhu belum mencapai $80{ }^{\circ} \mathrm{C}$ maka sensor akan terus membaca, dan apabila suhu sudah mencapai $80^{\circ} \mathrm{C}$ sensor akan berhenti membaca.

9. Buzzer akan berbunyi sebanyak lima kali, pada saat berbunyi sebanyak 5 kali maka pengguna harus memasukkan bahan kumbu bakpia ke dalam tempat pencampuran dan pemasakan

10. Pada tahap selanjutnya servo akan mengatur nyala api kecil, sehingga proses pemasakan dapat sesuai dengan pembuatan manual.

11. Waktu berjalan sesuai data input waktu, dimana apabila dipilih

12. Buzzer menyala sebanyak 7 kali, dan menginformasikan kepada pengguna bahwa alat sudah selesai memasak.

13. Servo bergerak ke $0^{\circ}$ dan api mati.

Apabila digunakan untuk memasak bakpia dalam waktu 8 jam kerja, mesin pengolah kumbu bakpia yang dikembangkan dapat mengolah $24 \mathrm{~kg}$ kacang ijo menjadi kumbu bakpia. Berdasarkan kondisi aktual, $1 \mathrm{~kg}$ kacang hijau dapat menghasilkan yang 100 butir bakpia atau 5 kardus bakpia, sehingga dengan penggunaan mesin akan mampu dihasilkan sebanyak 2400 butir bakpia atau 120 kardus bakpia. 
Mesin ini juga mampu meningkatkan efisiensi dan penggunaan waktu kerja, hal ini dikarenakan apabila digunakan untuk produksi, operator produksi dapat mengerjakan produksi lainnya.

\section{KESIMPULAN}

Berdasarkan upaya perancangan mesin pengolah kumbu bakpia automatis dengan menggunakan mikrokontroler Arduino Uno R3, apabila digunakan selama 8 jam/hari pemrosesan secara manual hanya mampu mengolah $2 \mathrm{~kg}$ kumbu bakpia per hari, sementara penggunaan mesin ini dapat meningkatkan produksi kumbu bakpia menjadi $24 \mathrm{~kg} / \mathrm{hari}$. Dengan demikian produksi bakpia akan meningkat dari 200 butir bakpia atau 10 kardus menjadi 2400 butir bakpia atau 120 kardus.

\section{UCAPAN TERIMA KASIH}

Penulis mengucapkan terimakasih kepada Direktorat Jenderal Penguatan Riset dan Pengembangan Kementrian Riset Teknologi dan Pendidikan Tinggi yang telah memberikan dukungan dalam pengembangan melalui bantuan Program Kemitraan Masyarakat (PKM) tahun 2018, serta kepada Rektor dan pimpinan LPPM Universitas Teknologi Yogyakarta yang telah memberikan banyak pengarahan.

\section{DAFTAR PUSTAKA}

[1] Prayito, Danu Edi, 2018, Perancangan Alat Kumbu Bakpia Di Kelompok Wanita Tani “Rahayu” Bangunharjo, Program Studi Teknik Industri, Universitas Teknologi Yogyakarta.

[2] Pahl. G., and Beitz, W. 2007, Engineering Design: Systematic Approach, $3^{\text {rd }}$ Edition, Springer Verlag, Berlin.

[3] Kannengeisser, U., da J.A. Gero, A Comparison Between Pahl And Beitz' Systematic Approach and The Design Behaviour Of Mechanical Engineering Students. Tersedia di http://mason.gmu.edu/ jgero/publications/Progress/15KannengiesserGe ro.EmpiricalSupport.pdf, diakses tanggal 21 Desember 2018.

[4] Motte, D., 2008, A Review of The Fundamentals of Systematic Engineering Design Process Models, International Design Conference Design, Croatio,

[5] Mendes, L. A., Back, N., and Oliveira, G. H. C., 2009, Designing automated test systems: An adapted methodology inspired on Pahl and Beitz's Systematic Approach, Robotics and Computer-Integrated Manufacturing, 25(6):pp. 945-950,

[6] Weiss, M, and Hari, A., 2015, Extension of the Pahl \& Beitz systematic method for conceptual design of a new product, Procedia CIRP 36, pp. $254-260$,

[7] Nursyahuddin, D., dan D. Gasni, 2014, Proses Perancangan Sistem Mekanik dengan Pendekatan Terintegrasi: Studi Kasus Perancangan Alat Uji Pin on Disc, TeknikA, Vol. 21, No. 1, Hal 14-29.

[8] Effendi, I.A, dan Ade Ramdan, 2014, Apllkasi Metode Perancangan Pahl-Beitz pada Perancangan Lini Produksi, Prosiding Seminar Nasional Teknologi Manufaktur Bandung.

[9] Putra, W. W., Redesain Meja dan Kursi Siswa di Yaketunis Yogyakarta, Invensi, Vol. 3, No. 1, 2018.

[10] Kamarudin, 2015, Modelling the Conceptual Design Process with Hybridization of TRIZ Methodology and Systematic Design Approach, Procedia Engineering 131, pp.1064 - 1072. 